\title{
Our study is published, the journey is not finished!
}

Olivier Pourret $^{1, *}$, Katsuhiko Suzuki $^{2}$, Yoshio Takahashi $^{3}$

${ }^{1}$ Institut Polytechnique UniLaSalle, AGHYLE, Beauvais, France olivier.pourret@unilasalle.fr

${ }^{2}$ Submarine Resources Research Center, JAMSTEC, Japan katz@jamstec.go.jp

${ }^{3}$ Department of Earth and Planetary Science, The University of Tokyo, Tokyo, Japan ytakaha@eps.s.u-tokyo.ac.jp

* Correspondence: olivier.pourret@ unilassalle.fr; Tel.: +33-3-44-06-89-79

Keywords: impact factor; metrics; citation; scholarly publishing. 


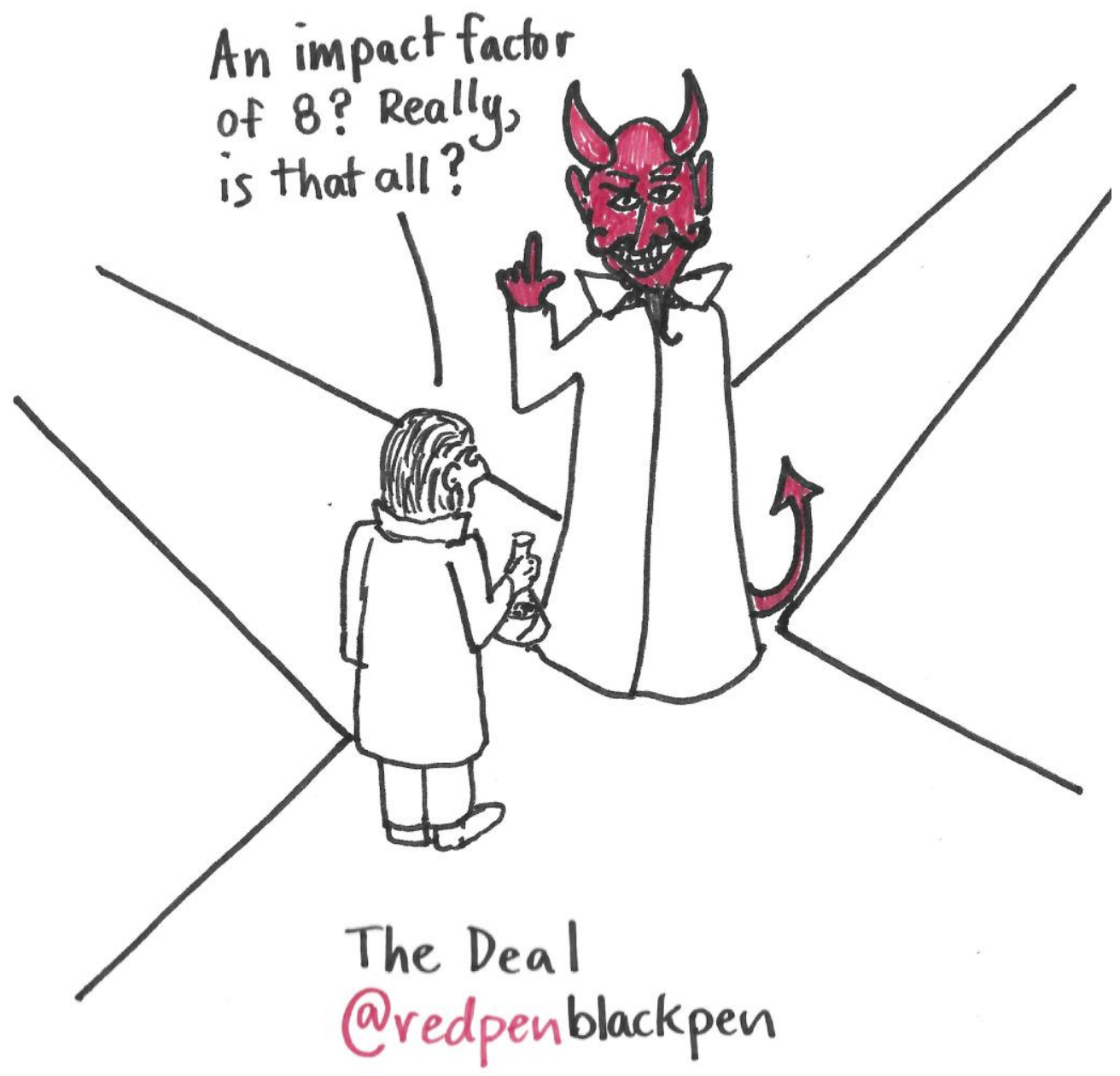

Source : Jason E. McDermott (@ redpenblackpen, https://twitter.com/redpenblackpen/status/1024181166478225408)

Each year, in June, we receive emails from publishers welcoming the evolution of their journals' "Journal Impact Factor" (JIF). But, what's behind this controversial metric (Callaway, 2016)? In the age of "publish and perish" (Harzing, 2007), we take much time and effort to write our papers and get them published-but how much time and effort do we put into finding readers 
or ensuring that we are reaching the right audience? Are metrics, such as the JIF, good guides for how well we are doing at reaching our target audience?

What is measured by bibliometrics such as the JIF? If we take the example of Geochemical Journal (the journal for which we are part of the Editorial Board) and consider citations in 2018 for articles published in 2016 and $2017(n=98)$, we find that $21 \%$ of the articles were cited $2+$ times, $18 \%$ once, and more than $60 \%$ not cited. For Elements $(n=76) 71 \%$ of articles published in 2016 and 2017 were cited 2+ times in 2018, 25\% one time, and only 4\% not cited. Figure 1 further shows citation distribution for six selected journals, along with their JIF and the percentage of citable items below the JIF. The citation distributions reveal that between $56 \%$ and $70 \%$ of articles from the selected journals panel have citations count below the reported JIF (Figure 1). Further analysis reveals that a few highly cited articles can inflate a JIF to a value that is not representative of all the articles. The JIF and many other arithmetic means are inappropriate statistics for measuring the impact of individual papers (and authors of those papers) (Tennant et al., 2019). And, such bibliometrics are not providing a measure for the visibility of your work or whether it is reaching your target audience. We need more informative and readily available article-level metrics, such as article citation counts or 'altmetrics', along with other qualitative and quantitative measures of research 'impact'. 

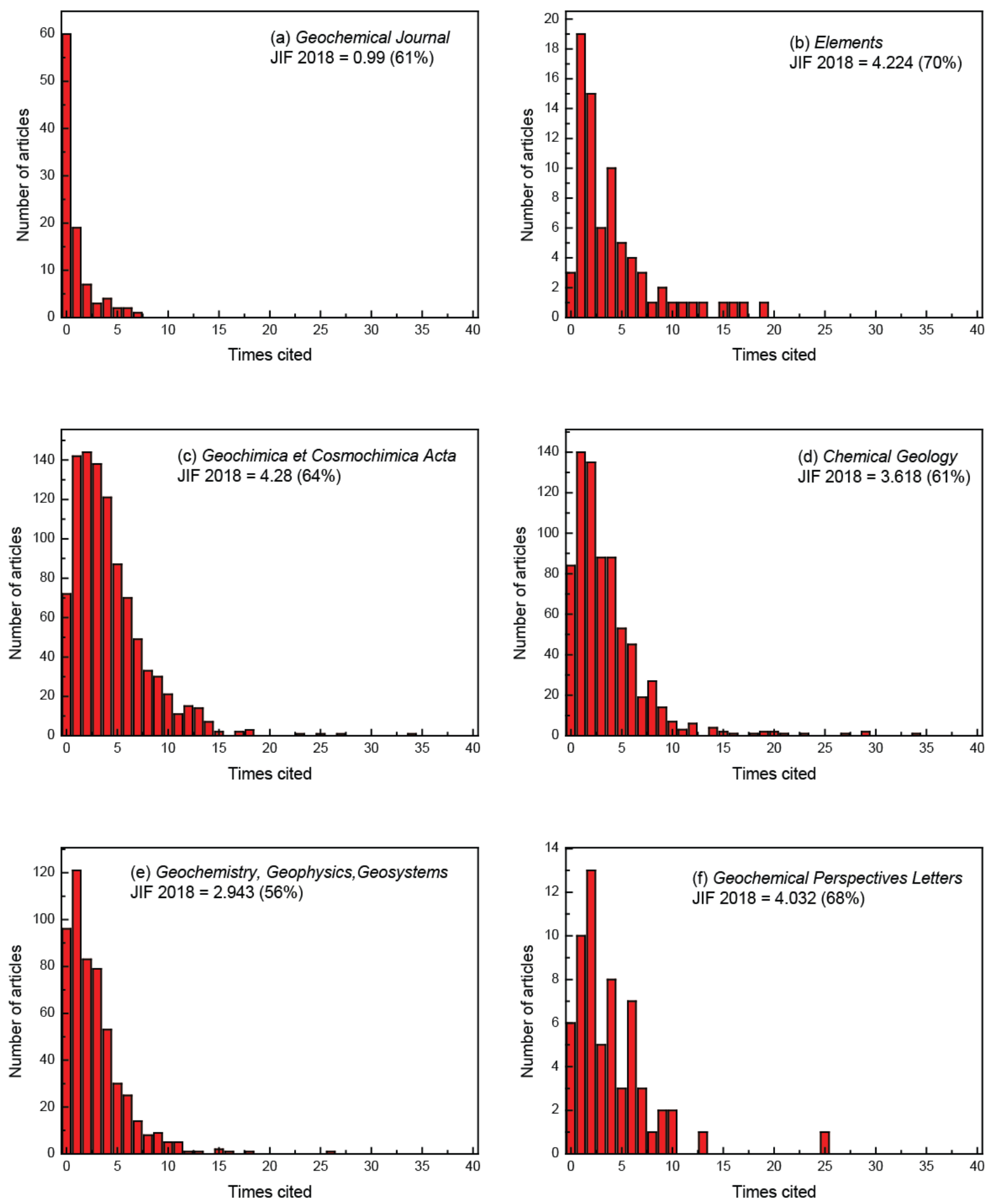

Figure 1 Data citations distribution for six selected journals. Each plot reports the 2018 JIF and the percentage of citable items below the JIF (between parentheses). Number of citations in 2018 
for articles published in 2016 and 2017 (Source Web of Science May 2020) (a) Geochemical Journal, (b) Elements, (c) Geochimica et Cosmochimica Acta, (d) Chemical Geology, (e) Geochemistry, Geophysics, Geosystems, (f) Geochemical Perspectives Letters.

The first step to ensure that our work reaches the right audience is to make our work widely accessible, such as found with Open Access (Pourret, 2020). But accessibility does not mean that our target audience will "see" our work. There are thousands of journals available and no one has the time or resources to read every publication! So, the second step to ensure that our work reaches the right audience is drawing attention to our work, creating a community, and engaging the public. As written by Ludden et al. (2015) "we are not so good at promoting the social and economic impacts of geochemistry". Online methods of communication (e.g., Twitter, Reddit, Facebook, blogs) have often had a bad reputation within scientific circles and are often not perceived as scholarly. Yet, we should utilize these platforms to draw attention to our scientific work. It can be something as simple as writing a blog post, participating in a science communication podcast or just tweeting about our latest findings (Green, 2019), drawing a scientific comics or sketch note (McDermott et al., 2018).

It is also important that the knowledge we produce can quickly reach the people for whom it is relevant. This is why engaged researchers are often visible in public circles rather than just within academic circles: they are frequent guests in traditional mass media such as newspapers, radio and television, and they are happy to give popular academic presentations to non-experts. The most important thing is that our knowledge is dispersed and gets where it can be understood and used. 
The value of a journal and the work published within it is also the community it creates. Elements is well-known and established journal in the geochemical community for great papers dealing with the topics from the Critical Zone to planetary systems. The magazine also publishes society news and lists of scientific events with the intent to draw together a community of researchers that would otherwise be disconnected. Elements is also used by many of you in classrooms (Pourret, 2009), and many of you read the magazine to just learn about topics within Earth sciences. Other than the published articles, none of the other uses result in measurable citations yet all have a significant impact on the reader.

Fortunately, there are metrics ('Alternative Metrics' popularly known as 'altmetrics') that can capture the impact of our work beyond citation counts in journals (Priem et al. 2010). Altmetrics (e.g., Altmetric https://www.altmetric.com/, PlumX Metrics https://plumanalytics.com/) have been shown to circumvent several weaknesses of citation counts as indicators for scientific attention: (1) they can be collected for articles, books, book chapters, presentations, figures ...; (2) they are available much faster than citation counts (Thelwall et al., 2013); (3) they can reflect the resonance of our work among non-scientific or non-traditional audiences (e.g., mainstream media). In addition to altmetrics, there are other tentative alternatives to the JIF, such as the TOP Factor, which is based primarily on the Transparency and Openness Promotion (TOP) Guidelines (Nosek et al., 2015).

Metrics are needed. But metrics are numerous and we have to be careful of using a single metric to measure the impact of our work. Both bibliometrics and altmetrics come with their shortcomings and yet-unsolved challenges (Lemke et al., 2019). We need to work together to find more appropriate measures of quality for authors and research. For a start, research 
excellence should be remodeled around transparent workflows and accessible research results (Hicks et al., 2015).

Science must go on! So, where will you publish your work and how will you measure its "value to the community"? A system based on bibliometric parameters favors an approach to "quantity over quality," and undervalues achievements such as societal impact. The best decisions are taken by combining robust statistics with sensitivity to the purpose and nature of the assessed research. There is a need for both quantitative and qualitative evidence; each is objective in its own way. Ultimately, we need to find a way for researchers and their work to be assessed in a way that is fair and accurate, and not over-reliant on publication metrics.

\section{References}

Callaway, E. (2016) Beat it, impact factor! Publishing elite turns against controversial metric. Nature 535, 210-211.

Green, T. (2019) Maximizing dissemination and engaging readers: The other 50\% of an author's day: A case study. Learned Publishing 32, 395-405.

Harzing, A.W. (2007) Publish or Perish.

Hicks, D.; Wouters, P.; Waltman, L.; de Rijcke, S.; Rafols, I. Bibliometrics: The Leiden Manifesto for research metrics. Nat. News 2015, 520, 429. 
Lemke, S., Mehrazar, M., Mazarakis, A., Peters, I., 2019. "When You Use Social Media You Are Not Working": Barriers for the Use of Metrics in Social Sciences. Frontiers in Research Metrics and Analytics, 3(39). doi:10.3389/frma.2018.00039.

Ludden, J.; Albarède, F.; Coleman, M., The Impact of Geochemistry. Elements 2015, 11 (4), 239-240. doi:10.2113/gselements.11.4.239.

McDermott JE, Partridge M, Bromberg Y (2018) Ten simple rules for drawing scientific comics. PLOS Computational Biology 14(1): e1005845.

Nosek, B. A.; Alter, G.; Banks, G. C.; Borsboom, D.; Bowman, S. D.; Breckler, S. J.; Buck, S.; Chambers, C. D.; Chin, G.; Christensen, G.; Contestabile, M.; Dafoe, A.; Eich, E.; Freese, J.; Glennerster, R.; Goroff, D.; Green, D. P.; Hesse, B.; Humphreys, M.; Ishiyama, J.; Karlan, D.; Kraut, A.; Lupia, A.; Mabry, P.; Madon, T.; Malhotra, N.; Mayo-Wilson, E.; McNutt, M.; Miguel, E.; Paluck, E. L.; Simonsohn, U.; Soderberg, C.; Spellman, B. A.; Turitto, J.; VandenBos, G.; Vazire, S.; Wagenmakers, E. J.; Wilson, R.; Yarkoni, T., Promoting an open research culture. Science 2015, 348 (6242), 1422-1425. doi:10.1126/science.aab2374.

Pourret, O., Global Flow of Scholarly Publishing and Open Access. Elements 2020, 16 (1), 6-7. Pourret, O., Elements in the classroom. Elements 2009, 5 (3), 195.

Priem, J., Taraborelli, D., Groth, P., and Neylon, C. (2010). Altmetrics: A Manifesto. Available online at: http://altmetrics.org/manifesto/.

Tennant, J. P.; Crane, H.; Crick, T.; Davila, J.; Enkhbayar, A.; Havemann, J.; Kramer, B.; Martin, R.; Masuzzo, P.; Nobes, A., Ten hot topics around scholarly publishing. Publications 2019, 7 (2). 
Thelwall, M.; Haustein, S.; Larivière, V.; Sugimoto, C. R., Do altmetrics work? Twitter and ten other social web services. Plos One 2013, 8 (5), e64841-e64841. doi:10.1371/journal.pone.0064841. 